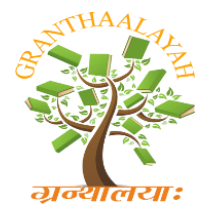

INTERNATIONAL JOURNAL OF RESEARCH GRANTHAALAYAH

A knowledge Repository

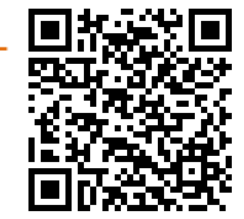

Arts

\title{
BAWDI: THE ELOQUENT EXAMPLE OF HYDROLIC ENGINEERING AND ORNAMENTAL ARCHITECTURE
}

\author{
Dr. Anjali Pandey ${ }^{* 1}$ \\ ${ }^{* 1}$ Assistant Professor (Drawing \& Painting), Govt. M.L.B. Girls P.G. College, Bhopal, INDIA
}

\begin{abstract}
"The secular Indian architecture includes town planning, palaces, general houses and forts of various categories. There was a constant growth in forms of this architecture from the period of harappan culture up to the Vijaynagar epoch. The towns were protected by walls (prakara) and the moats parikha. Each town provided places of general public utility, such as temples, stupas, schools, hospitals, markets, gardens and ponds".'
\end{abstract}

Keywords:

Hydrolic Engeering, Ornamental Architecture, Bawdi, Indian architecture.

Cite This Article: Dr. Anjali Pandey, "BAWDI: THE ELOQUENT EXAMPLE OF HYDROLIC ENGINEERING AND ORNAMENTAL ARCHITECTURE" International Journal of Research - Granthaalayah, Vol. 4, No. 1 (2016): 217-222.

\section{INTRODUCTION}

Bawdi are usually known as Stepwell, Stairwells, Baori, Baoli or Vav. It is the manmade pond with significant ornamental architectural structure for water conservation of ancient India. These wells are commonly found at western region of India for irrigation and storage of water mainly to cope with seasonal fluctuations. ${ }^{2}$

Water Exploitation and management have been of great concern for a developing and developed urban civilization that the Harappans created. The most ancient example of water management is found from proto-historic period, primarily from harappan sites. The hydraulic structures from Mohenjo-Daro (undivided India) are eloquent examples which attain the phenomenon excellence. The great bath, the sanitary, drainage and public wells were the first steps to exploit ground water. ${ }^{3}$

"This kind of efficient system of Harappans of Dholavira, developed for conservation, harvesting and storage of water speaks eloquently about their advanced hydraulic engineering, given the state of technology in the third millennium B.C."-R.S.Bist ${ }^{4}$, 
The city Dholavira had massive reservoirs there of which some are exposed. The water conservation of this city was based on rain water harvesting, it is a complex water system comprising of large rocket reservoirs. The water drew from seasonal streams conserve the life system and supports in harvesting the parched landscape. The exclusive water management system was designed to consume each and every drop of available water. It is the

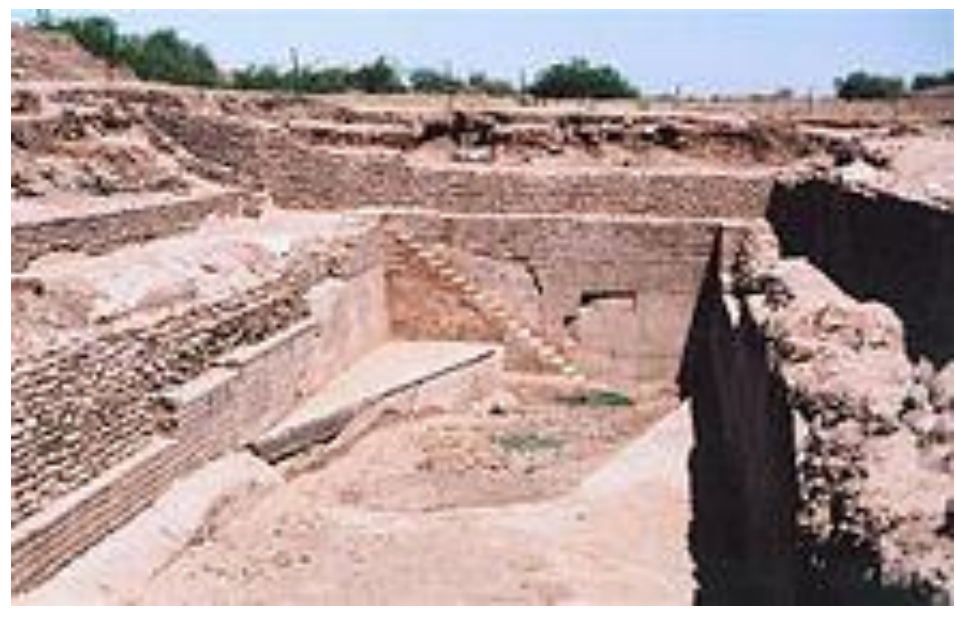
unique and the most efficient supportive system against harsh and hot arid climate. In ancient India, near about 3000 to 800 B.C. the climate played the major role which added the new dimensions in the personality of ancient Indian civilizations. Stepwell were excavated to reach the underground water level sever stylistic stories were made to reach there. ${ }^{5}$ In ancient and mediaeval age Bawdi were constructed under patronage of royal, or wealthy or powerful persons $^{6 .}$ The majority of serving stepwells were originally served as laser, religious and ceremonial purpose as well as providing the water. At this place the women were also associated with these wells. Some of the famous examples of these types of wells in India are:

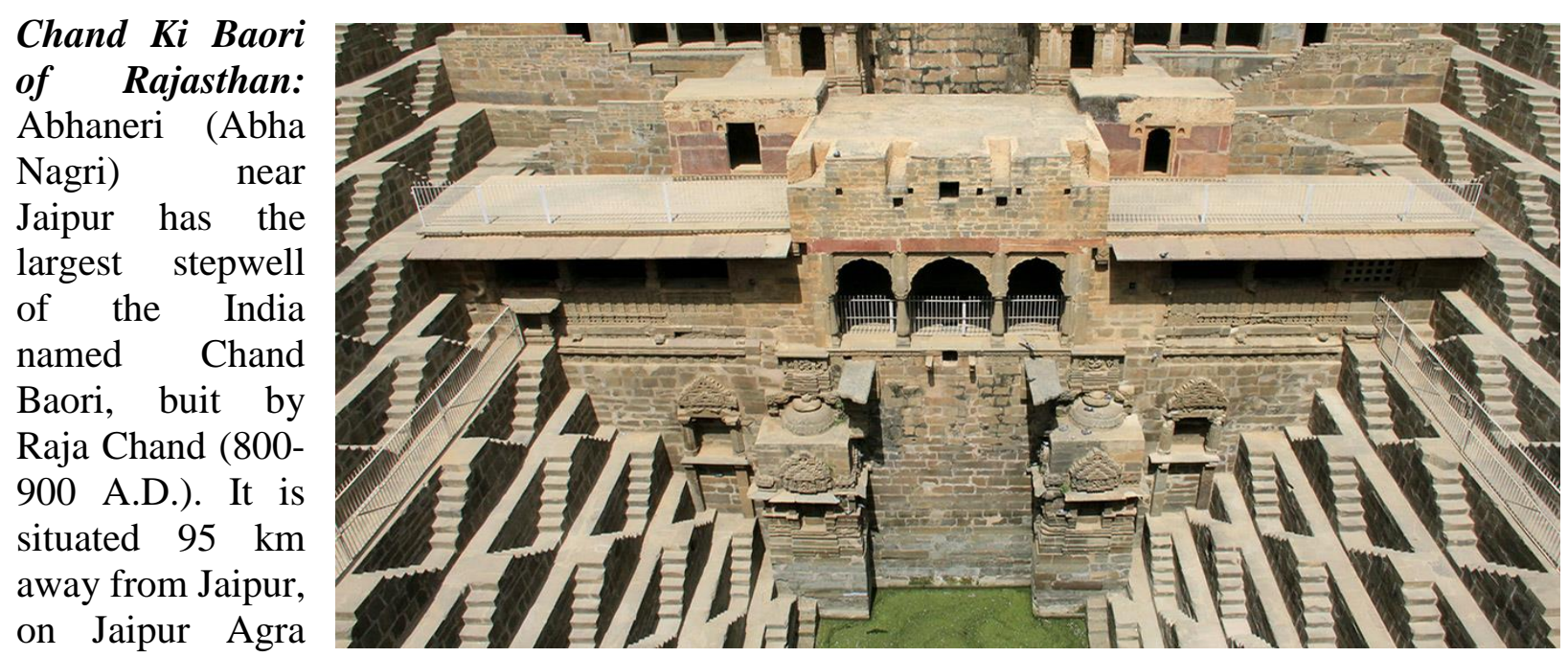

road on the opposite side the temple of Harshat mata (goddess of joy and happiness). It is the fine example of fine architectural expertise. The Chand baori has thirteen stories with 3500 steps. ${ }^{7}$ It is the deepest one in World ${ }^{8}$. It is the marvelous example of glorious past. Another Baori of Rajasthan state is at Boondi which is also multistoried water building with magnificent carving on pillars.

The famous Ran Ki Vav of Patan of Gujarat has been declared World Heritage by UNESCO. The Vav having elegant multistoried pavilions and is the unique example of embellished architecture of $11^{\text {th }}$ Century A.D which is situated on the bank of river Saraswati. ${ }^{9}$ The architectural style elaborates the complex technique and the design form with more than five 
hundred sculptures which shows the heights of craftsmanship. The sculputures are Mahishasur mardani, dashavatar, apsaras, are some of them ${ }^{10}$.

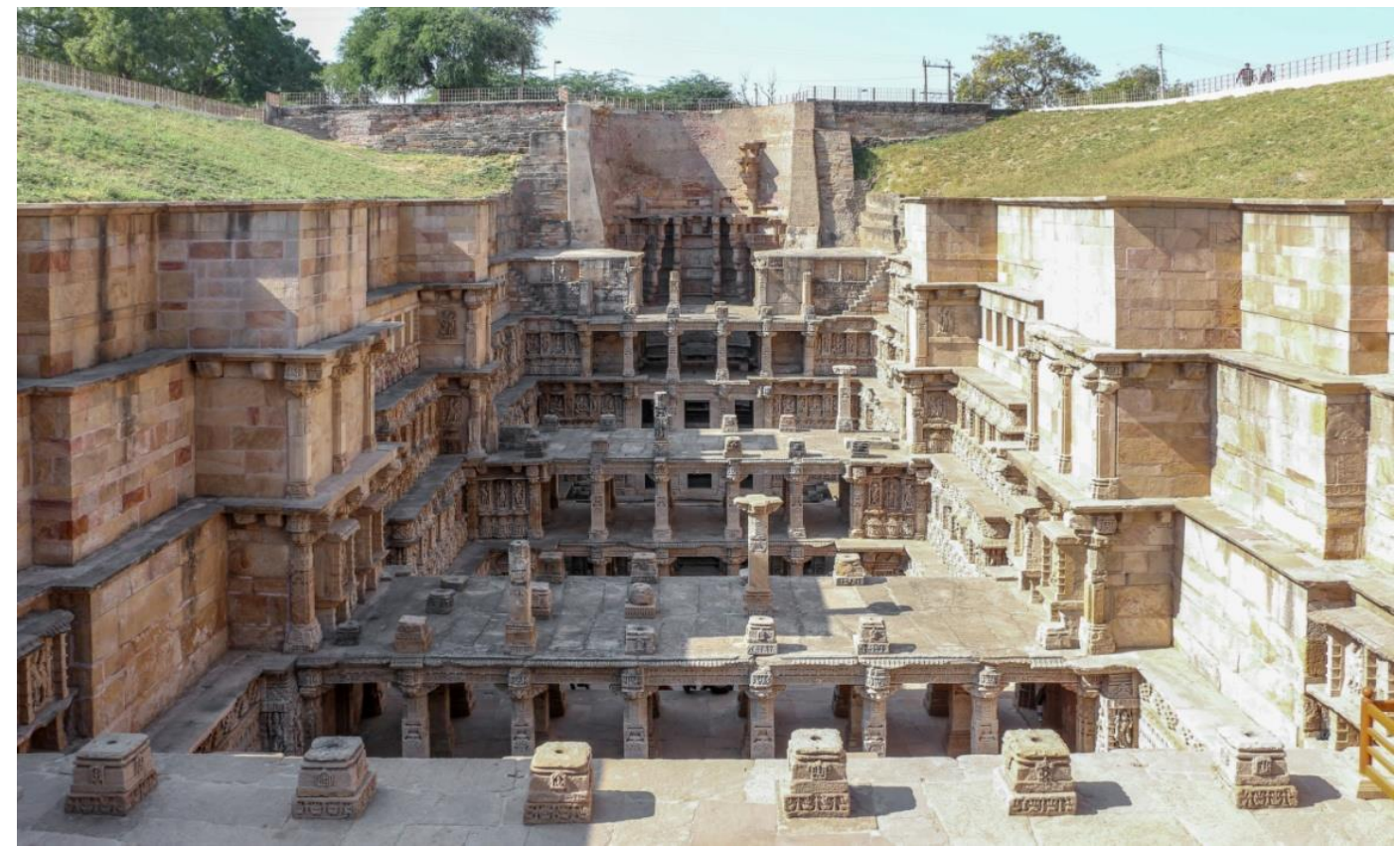

The Ahmadabad of Gujarat has a famous five storied stepwell known as Adlaj is also famous for its magnificent structure. It is the fusion of Islamic and Hindu architecture and design built by Rani Rudabai wife of Rajput noble Vikram Shah Vaghela in1499 A.D. Idols of Hindu gods and goddess, columns and balconies decorated with flora and fauna motifs. ${ }^{11}$

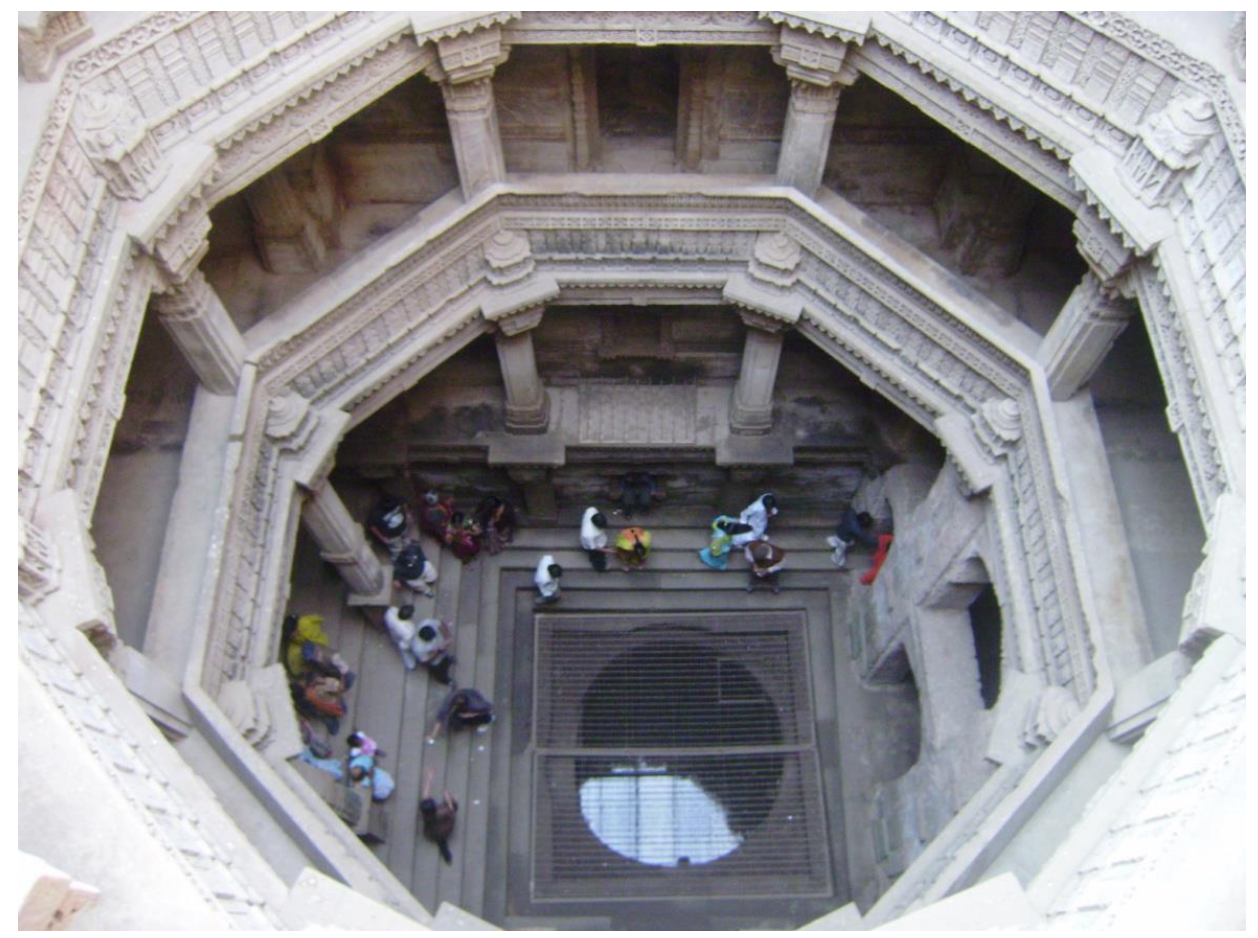




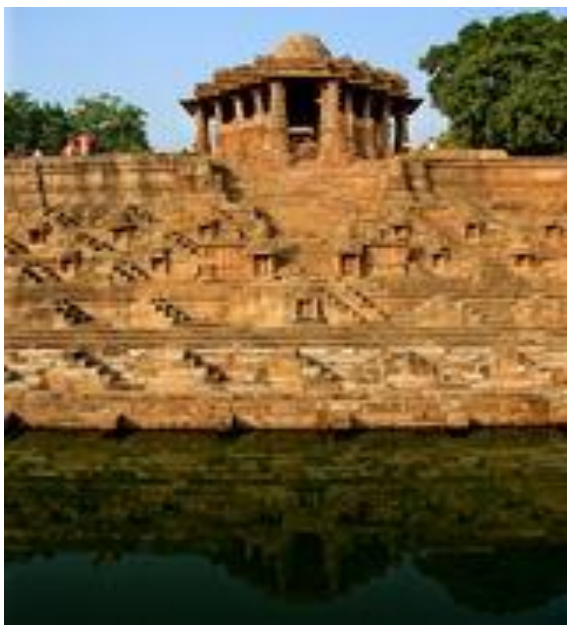

The sun temple of Modhera is situated in Gujrat, It was built by Raja Bhimdev in 1026 A.D. of solanki Dynasty. It has the well known Surya Kund with its finest geometrical designed rectangular architecture. The dazzling patterns of steps leads to the $53.6 \times 36.6 \mathrm{mts}$ rectangular stepped tank which is known as Surya kund. 108 miniature shrines are carved in between the stairs. The compositions of the steps are made in shape of pyramid. Lord Vishnu, Ganesh, Nataraj, Sheetlamata and other idols are carved as reservoirs deities. ${ }^{12}$

At the capital of India, Delhi, Agrasen Ki Baoli and Rajan Ki Baoli which are under the protection of archeological survey of India are noted stepwells for their historical and architectural aspect. The Agrasen Baoli which is three storied has 108 steep steps with $58.52 \times 13.70 \mathrm{mts}$ ground level area. The architecture of baoli is of Mughal style with thick walls on both the sides consisting series of arch and false niches. False niches might be made for design purpose. Passages and rooms are made inside it. It is said that this baoli was made by Maharaja Agrasen. ${ }^{13}$

The Pushkarni and Lakkundi stepwells of $15^{\text {th }}$ century Chalukya period also attracts the large number of tourists at Hampi. ${ }^{14}$

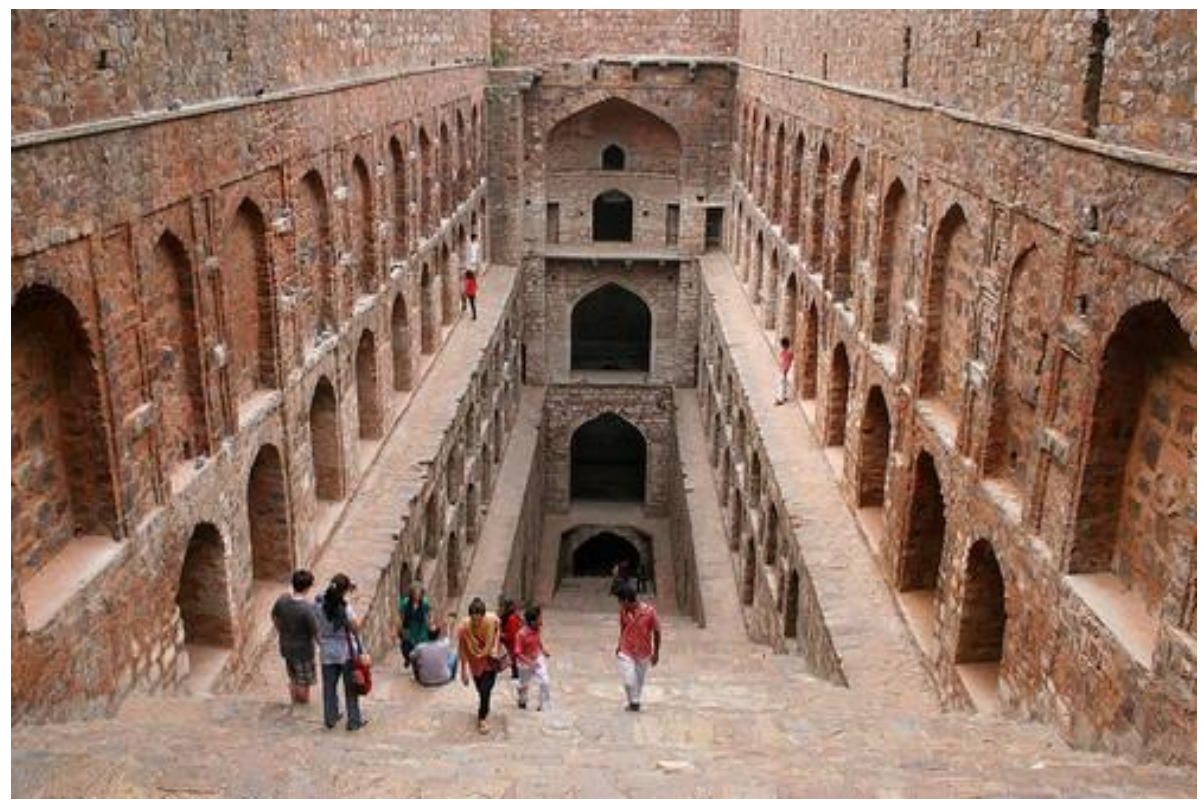

\section{ARCHITECTURAL DESIGNING}

The concept of stepwell was actually originated in India. It is popular throughout the years for its architectural and water engineering. Baori provided the water for drinking, washing, bathing and harvesting. Actually they were originated as reservoirs and storage tanks and functioned as 
Hindu temples elaborated as stylish stone carving on columns and shed pavilions. The travelers, pilgrims and the caravans stay here during heat of the day or overnight.

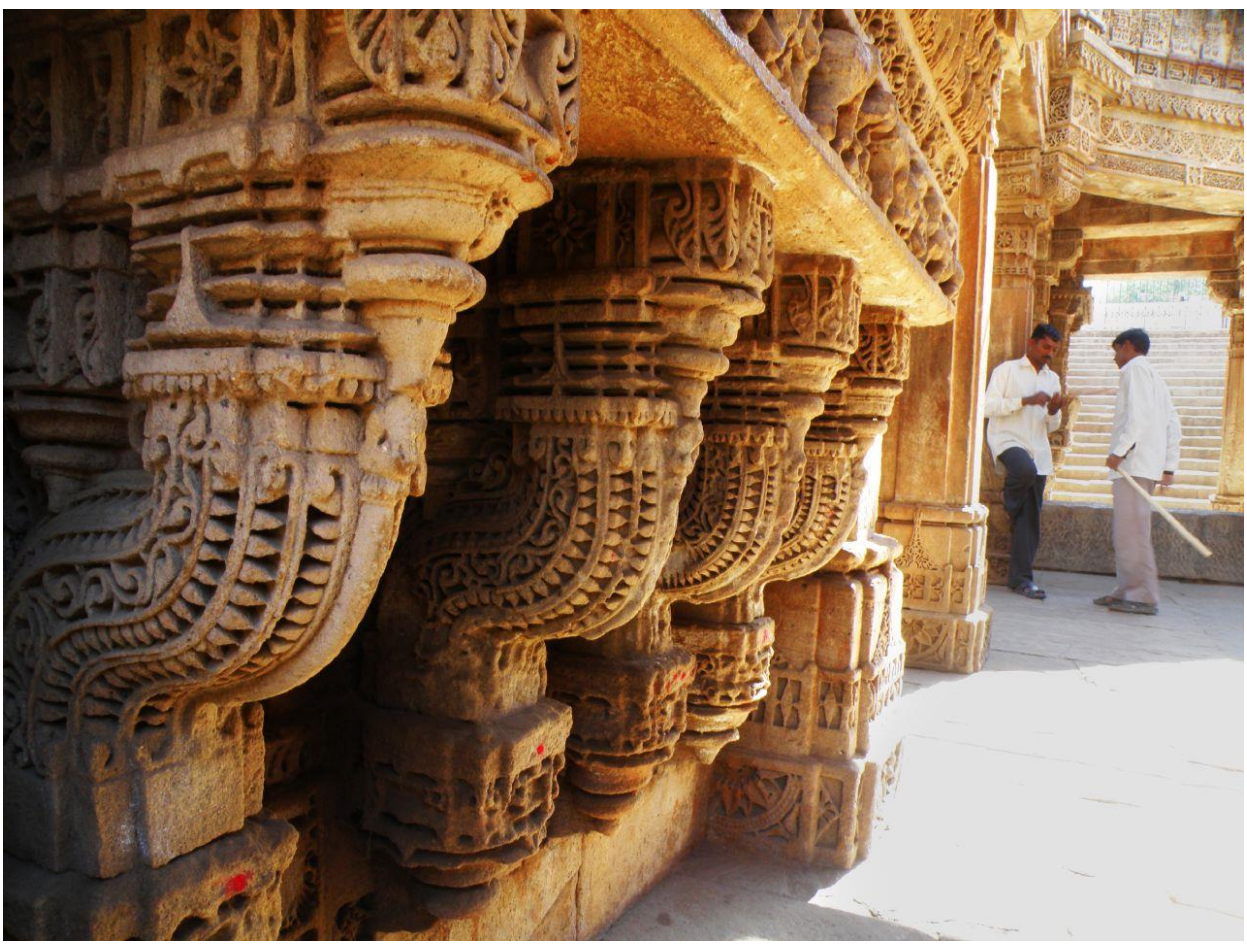

days. The chambers are often decorated with carved or arched pillars.
The deep trenches were digged in the earth in order to get water throughout the year; block of stones were used to make the wall. Upside stairs were made for leading down to the water surface. The structure of stepwell mainly consists two parts one is used as water storage purpose and the galleries and chambers to provide as cool and calm retreat to the travelers during hot

The Baori were generally structured with several stories let down steps to the bottom. Sometimes the complex engineering of Hindu and Islamic architecture made them stylish and unique. The Islamic version offers the arched side-niches while the Hindu architecture is full of decorative columns and pillars. Some of the bawdi are the fusion of Indo-Islamic culture.

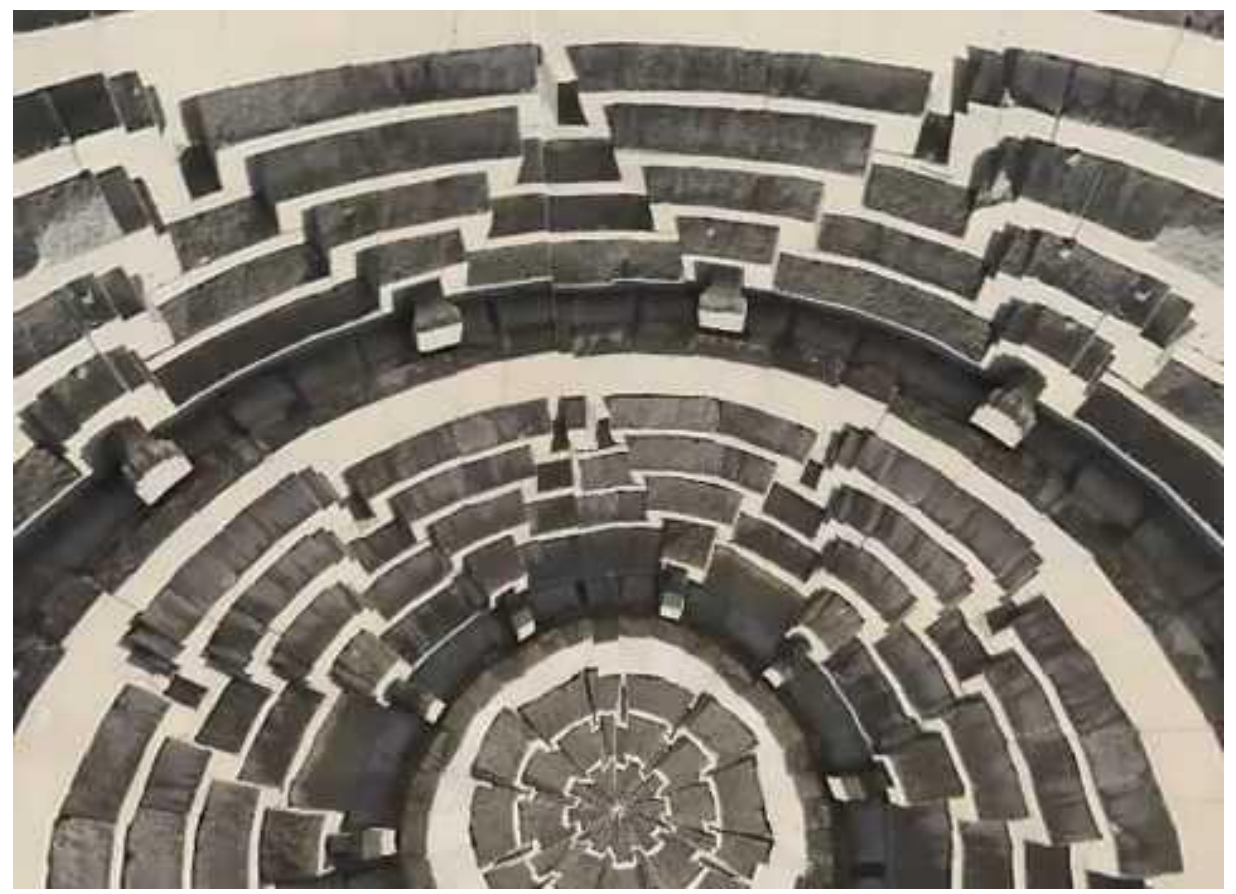


The transformation of 'Karu Kala' (utilitarian art) in 'charu kala' fine arts can be seen in magnificent form of stepwells from proto historic to historical age. The unique structure of water engineering later takes the changes aesthetically in historic period and identified them the superb mesmerizing monuments of water conservation in ancient India.

\section{REFERENCES}

[1] Bajpai K.D., Five Phases of Indian Art; Introduction; Pg- 1-2

[2] Wikipedia.org

[3] Bisht R.S., Harappan Hydro-Engineering and Water Management .( PDF)

[4] Ibid

[5] Britanica.com, Stepwell/architecture/britanica.com

[6] Ibid ibid

[7] Wikipedia.org

[8] www.indiamarks.com

[9] Asi.nic.in

[10] Wikipedia.org

[11] Desai

[12] Gujrattourism.com/wekipedia

[13] Thedivineindia.com

[14] Hampi.in 